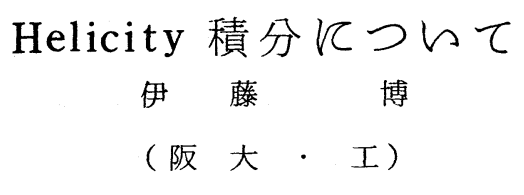

( 1983 年 9 月 26 日 受 理)

\title{
Theory of Helicity Integrals
}

H. Ito

(Received September, 26, 1983)

\begin{abstract}
A new helicity integral which denotes the degree of knottedness of the plasma current is introduced with respect to confined plasmas. Time evolutional equations of both magnetic and current helicities are derived in case of the presence of the electric resistivity. Both integrals decrease with respect to the time when the system is enclosed by a perfectly conducting rigid wall.
\end{abstract}

\section{ミ1。まえがき}

核融合の理論分野において注目を浴びているものの一つに, helicity 積分がある。すなわちべク トルポテンシャル $\mathbf{A}$ と磁場Bのスカラー積の空間積分量であり, それが不変量であるてとから, 特に 変分的手法の中によく使用されている。文献によるととの磁気 helicity が時間的または流れにそっ て不変量であるととを示したのはWoltjer ${ }^{1)}$ が最初であり, てれに続いて Moffatt ${ }^{2}$ ), 独立に J. B. Taylor $^{3)}$ というととである。この量は離散的モデルならば磁力線のからみ合いの度合を示すととに なるけれど, 連続的分布では物理的に極めてとらえにくい。そのためその物理像をとらえるより, 例 えば変分の副条件に使用してみてその結果から逆に本質を調べようという動きが現在も続いていると いってよい4）。例えば全磁気エネルギーを変分関数にとり，K積分（磁気helicity）を副条件にす ると容易に磁場と電流の force-free の式が出るととはよく知られている。しかしながら真空中に 存在するひとつの電流環を考えたとすると, 明らかにK積分は存在しない。前出のMoffatt の論文

Plasma Physics Laboratory, Faculty of Engineering Osaka University. Yamada-oka 2-1 Suita Osaka 


\section{伊藤}

はもともと流体の渦輪の理論であり, K 積分の発祥は流れの速度場と渦度のスカラー積の体積積分か らきている。ついで彼はそれをMHD理論にもちてみK積分の不変性を証明しているけれど，渦輪同 志のからみ合わせの度合という定義を忘れるわけにいかない。一方プラズマにおいて最も重要な関係 は電流と磁場であり, ベクトルポテンシャルは直接観測を行わない量である。さらに必要なととは非 可逆過程, すなわち, プラズマの比抵抗值とか粘性などが存在する時, K積分のような量がどのよう に変化するかというととに最も興味があるが, 今日まで明確にはされていないようである。ての論文 では, 磁気helicity について著者が考えたととと, それに代わるもう一つの不変量を導き, 非可逆 過程におけるK積分の時間変化を論じるととにする。

\section{§ 2. $\mathrm{M}$ 積分の導入}

磁気helicity 積分は

$$
\mathrm{K}=\int_{\mathrm{V}} \mathbf{A} \cdot \mathbf{B} \mathrm{d} \tau
$$

で定義される。この不変性は多くの人によって証明されているけれぞ, 最も厳密なのは, Moffattの それである。とてでは証明そのもが目的ではないが, 新しい不変量の導入のために繰り返してみる。 一般に,

$$
\frac{\mathrm{DK}}{\mathrm{Dt}}=\int_{\mathrm{V}} \frac{\mathrm{D}}{\mathrm{Dt}}\left(\frac{\mathbf{A} \cdot \mathbf{B}}{\rho}\right) \rho \mathrm{d} \tau+\int_{\mathrm{V}} \frac{(\mathbf{A} \cdot \mathbf{B})}{\rho} \frac{\mathrm{D}}{\mathrm{Dt}}(\rho \mathrm{d} \tau)
$$

とかけ，

$$
\frac{\mathrm{D}}{\mathrm{Dt}}(\rho \mathrm{d} \tau)=0 \quad\left(\frac{\partial}{\partial \mathrm{t}}+\mathbf{v} \cdot \nabla=\frac{\mathrm{D}}{\mathrm{Dt}}\right)
$$

から,

$$
\frac{\mathrm{DK}}{\mathrm{Dt}}=\int \frac{\mathrm{D}}{\mathrm{Dt}}\left(\frac{\mathbf{A} \cdot \mathbf{B}}{\rho}\right) \rho \mathrm{d} \tau
$$

を計算するのが流体力学の一般的手法である。そてで,

$$
\frac{\mathrm{D}}{\mathrm{Dt}}\left(\frac{\mathbf{A} \cdot \mathbf{B}}{\rho}\right)=-\frac{1}{\rho^{2}} \frac{\mathrm{D} \rho}{\mathrm{Dt}}(\mathbf{A} \cdot \mathbf{B})+\frac{1}{\rho} \frac{\mathrm{D}}{\mathrm{Dt}}(\mathbf{A} \cdot \mathbf{B})
$$

の右䢌の第二項を計算するととにする。

$$
\frac{\partial}{\partial \mathrm{t}}(\mathbf{A} \cdot \mathbf{B})=-2 \mathbf{E} \cdot \mathbf{B}-\operatorname{div}(\mathbf{E} \times \mathbf{A})
$$


Helicity 積分について

であるから

$$
\frac{\mathrm{D}}{\mathrm{Dt}}(\mathbf{A} \cdot \mathbf{B})=-2 \mathbf{E} \cdot \mathbf{B}-\operatorname{div}(\mathbf{E} \times \mathbf{A})+(\mathbf{v} \cdot \nabla)(\mathbf{A} \cdot \mathbf{B}) 。
$$

第一項は

$$
\frac{\mathrm{D} \rho}{\mathrm{Dt}}(\mathbf{A} \cdot \mathbf{B})=\rho(\mathbf{A} \cdot \mathbf{B})+(\mathbf{A} \cdot \mathbf{B})(\mathbf{v} \cdot \nabla \rho)
$$

となるから(3), (4), (5)をまとめて

$$
\begin{aligned}
\int \frac{\mathrm{D}}{\mathrm{Dt}}\left(\frac{\mathbf{A} \cdot \mathbf{B}}{\rho}\right) \rho \mathrm{d} \tau= & \int\left\{-\frac{1}{\rho}(\mathbf{A} \cdot \mathbf{B})(\dot{\rho}+\mathbf{v} \cdot \nabla \rho)-2 \mathbf{E} \cdot \mathbf{B}\right. \\
& -\operatorname{div}(\mathbf{E} \times \mathbf{A})+(\mathbf{v} \cdot \nabla)(\mathbf{A} \cdot \mathbf{B})\} \mathrm{d} \tau
\end{aligned}
$$

と計算される。積分の括弧内は連続の方程式を用いて

$$
\begin{aligned}
& (\mathbf{A} \cdot \mathbf{B}) \operatorname{div} \mathbf{v}-2 \mathbf{E} \cdot \mathbf{B}-\operatorname{div}(\mathbf{E} \times \mathbf{A})+(\mathbf{v} \cdot \nabla)(\mathbf{A} \cdot \mathbf{B}) \\
= & \operatorname{div}\{(\mathbf{A} \cdot \mathbf{B}) \mathbf{v}-\mathbf{E} \times \mathbf{A}\}-2 \mathbf{E} \cdot \mathbf{B}
\end{aligned}
$$

と書きかえられる。そてで

$$
\int \frac{\mathrm{D}}{\mathrm{Dt}}\left(\frac{\mathbf{A} \cdot \mathbf{B}}{\rho}\right) \rho \mathrm{d} \tau=-2 \int \mathbf{E} \cdot \mathbf{B} \mathrm{d} \tau+\int_{\mathbf{S}}\{(\mathbf{A} \cdot \mathbf{B}) \mathbf{v}-\mathbf{E} \times \mathbf{A}\} \mathrm{d} \mathbf{S}
$$

器壁の上で

$$
\mathbf{v} \cdot \mathrm{d} \mathbf{S}=0, \quad \mathbf{E} \times \mathrm{d} \mathbf{S}=0, \mathrm{~B} \cdot \mathrm{ds}=0
$$

という条件で表面積分は零となり, 一般化オームの式,

$$
\mathbf{E}+\mathbf{v} \times \mathbf{B}=\eta \mathbf{j}
$$

を使うと

$$
\frac{\mathrm{D}}{\mathrm{Dt}} \int_{\mathrm{V}}(\mathbf{A} \cdot \mathbf{B}) \mathrm{d} \tau=-2 \eta \int_{\mathrm{V}} \mathbf{j} \cdot \mathbf{B} \mathrm{d} \tau
$$

が導かれる。そてで右辺の積分

$$
\mathrm{M}=\int \mathbf{j} \cdot \mathbf{B} \mathrm{d} \boldsymbol{\tau}
$$


をM積分と名付けるととにする5)。

\section{§3. 磁気流体的不変量}

現在までに取り上げられている不変量は次のような形をしている。2つのベクトルを，X，Yとし $\tau$

$$
\mathbf{Y}=\operatorname{rot} \mathbf{X}
$$

という関係があるとすると

$$
\mathrm{I}=\int \mathbf{X} \cdot \mathbf{Y} \mathrm{d} \tau
$$

という積分を定義する。

$$
\begin{array}{ll}
\mathbf{X}=\mathbf{U}, & \mathbf{Y}=\operatorname{rot} \mathbf{U}=\mathbf{W} \\
\mathbf{X}=\mathbf{A}, & \mathbf{Y}=\operatorname{rot} \mathbf{A}=\mathbf{B}
\end{array}
$$

とおくとそれぞれ渦, および磁力線の helicity が得られる。(8)の積分の特徵は表面積分が零という ととである。とのような類推によると前出のM 積分のほかに

$$
\int \mathbf{j} \cdot \operatorname{rot} \mathbf{j} \mathrm{d} \tau=\int \mathbf{j} \cdot \Gamma \mathrm{d} \tau
$$

も同様な性質があることが容易に想像できる。

(8)の形のほかに実は

$$
\int \frac{1}{2 \mu} B^{2} \mathrm{~d} \tau
$$

も,プラズマの比抵抗が零であれば保存するととが簡単に証明できる。しかし不変量が存在するから といって，それぞれが本質的に意味があるとはかぎらない。例えばWoltjer の取り上げた

$$
\int \mathbf{B} \cdot \mathbf{v} \mathrm{d} \boldsymbol{\tau} \quad\left(\boldsymbol{\nabla}=\mathbf{v}_{\mathrm{i}}-\mathbf{v}_{\mathrm{e}}\right)
$$

は実は $\mathrm{M}$ 積分の中に含まれるべきものである。 $\mathrm{M}$ 積分がK 積分と並んで必要と考えられる根拠の一つ は変分原理にある。著者は既に $\mathrm{K}$ 積分ならびに $\mathrm{M}$ 積分を副条件として平衡解を求める変分原理を導入 した ${ }^{5)}$ ○れは

$$
\delta\left(\int \mathrm{Pd} \tau+\beta \int \frac{1}{2 \mu} \mathrm{B}^{2} \mathrm{~d} \tau+\frac{\alpha}{2}\{\mathrm{~K} \text { or } \mathrm{M}\}\right)=0
$$

とかけ, 軸対称系, 直線ヘリカル系, FRCについていままで知られている解をすべて求め得るとい 
うととである。注目すべきととは副条件が $\mathrm{K}$ 積分であっても $\mathrm{M}$ 積分であっても同じ結果を得るという 点にある。(11) の解で特に軸対称の解を示しておく。円柱座標系で

$$
\begin{aligned}
& \mathrm{j}_{\mathrm{r}}+\alpha \mathrm{B}_{\mathrm{r}}=0 \\
& \mathrm{j}_{\mathrm{z}}+\alpha \mathrm{B}_{\mathrm{z}}=0 \\
& \mathrm{j}_{\theta}+\alpha \mathrm{B}_{\theta}=\mathrm{r} \frac{\mathrm{dP}}{\mathrm{d} \Psi} \quad\left(\Psi=\mathrm{rA}_{\theta}\right)
\end{aligned}
$$

こてで $\alpha$ は

$$
\alpha \mu=-\frac{\mathrm{dI}}{\mathrm{d} \Psi} \quad\left(\mathrm{I}=\mathrm{rBB}_{\theta}\right)
$$

で与えられる。ラグランジュの未定常数 $\alpha$ は壁までプラズマがあればそてまで一定であるが, リミタ 一などの存在で電流が $\mathrm{r}=\mathrm{r}_{\mathrm{s}}$ までしか存在しなければそてから先は零となり，（ $\mathrm{r}<\mathrm{r}_{\mathrm{s}}, \mathrm{r}>\mathrm{r}_{\mathrm{s}}$ でI は一定），真空磁界にうまくつながるとととなる。いずれにせよプラズマの内部ですら，ポロィ ダル方向ではforce - free の状態が実現しており, K積分の理論が force-free の条件によく使 用されているととと関連が深い。しかし平衡配位におけるforce-freeの実現は系の対称性から来 ているととを注意しておく。

\section{§ 4. M積分の意義と不変性}

$\mathrm{M}$ 積分が電流の結び具合と関係しているととはむしろK積分の磁力線のもつれ具合よりもっと具体

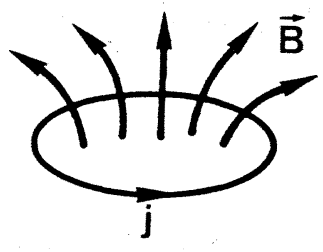

第1図

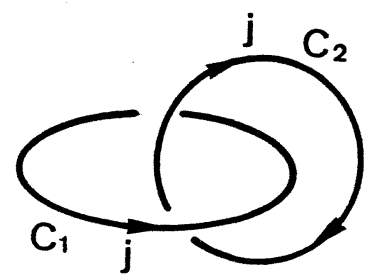

第 2 図 的に説明できる。第一図のような電流環とそれのつくる磁界 を考える。このような単一の電流環では磁界のベクトルは常 に直交する。すなわち

$$
\int \mathbf{j} \cdot \mathbf{B} \mathrm{d} \tau=0
$$

である。ととろが第二図のように二つの電流環がからみ合っ ていると積分は零とならず, 相互の電流の向きが図のような ら

$$
\int \mathbf{j} \cdot \mathbf{B} d \tau>0
$$

となる。一般にビオサバールの定理により， 


$$
\begin{aligned}
& \mathrm{M}=\int \mathbf{j} \cdot \mathbf{B} \mathrm{d} \tau=\frac{1}{4 \pi} \int \frac{\mathbf{R} \cdot\left[\mathbf{j}(\mathbf{r}) \times \mathbf{j}\left(\mathbf{r}^{\prime}\right)\right]}{\mathrm{R}^{3}} \mathrm{~d} \tau \mathrm{d} \tau^{\prime} \\
& \mathbf{R}=\mathbf{r}-\mathbf{r}^{\prime}
\end{aligned}
$$

もし $\mathbf{r} \in \mathrm{C}_{\mathrm{i}}, \quad \mathbf{r}^{\prime} \in \mathrm{C}_{\mathrm{i}}$ という二つの電流環 $\mathrm{C}_{\mathrm{i}}, \mathrm{C}_{\mathrm{j}}$ についていうなら

$$
\mathrm{M}=\frac{1}{4 \pi}\left(\mathrm{j}_{\mathrm{i}} \mathrm{j}_{\mathrm{j}}\right) \oint_{\mathrm{C}_{\mathrm{i}}} \oint_{\mathrm{C}_{\mathrm{j}}} \frac{\mathbf{R} \cdot \mathrm{d} \boldsymbol{\ell}_{\mathrm{i}} \times \mathrm{d} \boldsymbol{\ell}_{\mathrm{j}}}{\mathrm{R}^{3}}=\alpha_{\mathrm{ij}}\left(\mathrm{j}_{\mathrm{i}} \mathrm{j}_{\mathrm{j}}\right)
$$

とかける。 $\boldsymbol{\ell}_{\mathrm{i}}, \boldsymbol{\ell}_{\mathrm{j}}$ は $\mathrm{C}_{\mathrm{i}}, \mathrm{C}_{\mathrm{j}}$ の切線ベクトルである。 $\alpha_{\mathrm{ij}}$ の值は位相幾何学的にいえば第三 図のようになる。（14) 式を一般化して

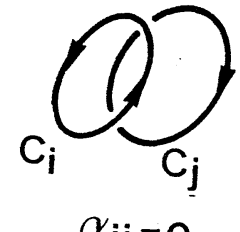

$\alpha_{\mathbf{i j}}=0$

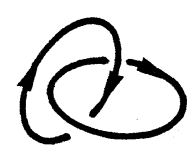

$\alpha_{i j}=1$

第 3 図

$$
\mathrm{M}=\sum_{\mathrm{m}>\mathrm{n}}^{\sum_{\mathrm{n}}} \alpha_{\mathrm{mn}} \mathrm{j}_{\mathrm{m}} \mathrm{j}_{\mathrm{n}}
$$

とかけ，例えば核融合装置のすべてについてモ デル的, 位相幾何学的にすぐ計算できるもので ある。

次にM積分の不変性について論じよう。K積 分は既に証明したようにかなり広い条件で不変

性が証明できた。M積分の方は必ずしもそうではなく，結論をいってしまえば平衡プラズマ中におい いて保存する。したがってむしろ核融合研究においてK 積分以上に注目すべき量というととができよ う。このような量を扱うのにプラズマの二流体モデルが適当である6)。すなおちイオンと電子の二成 分系でその重心速度は系が平衡にあるとして零であり, 存在するのは相対速度のみとする。

$$
\begin{aligned}
& \rho \mathbf{V}=\rho_{\mathrm{i}} \mathbf{\nabla}_{\mathrm{i}}+\rho_{\mathrm{e}} \mathbf{\nabla}_{\mathrm{e}}=0 \\
& \mathbf{v}=\mathbf{v}_{\mathrm{i}}-\mathbf{v}_{\mathrm{e}}
\end{aligned}
$$

ことでプラズマの電気的中性を仮定して $\mathrm{n}_{\mathrm{i}}=\mathrm{n}_{\mathrm{e}}=\mathrm{n}$ とした。イオン, 電子の質量をそれぞれ, $\mathrm{M}, \mathrm{m}$ にすると

$$
\mathbf{j} \cdot \mathbf{B}=\mathrm{ne} \mathbf{v} \cdot \mathbf{B}=\frac{\mathrm{e}}{\mathrm{M}+\mathrm{m}} \rho \mathbf{v} \cdot \mathbf{B}
$$

から

$$
\frac{1}{\rho}(\mathbf{j} \cdot \mathbf{B})=\frac{\mathrm{e}}{\mathrm{M}+\mathrm{m}} \mathbf{v} \cdot \mathbf{B}=\mathrm{k} \mathbf{v} \cdot \mathbf{B}
$$

の流れ $\mathbf{v} そ う$ 時間変化を計算する。磁界および相対速度の時間変化は 


$$
\frac{\mathrm{D} \mathbf{B}}{\mathrm{Dt}}=-\operatorname{rot} \mathbf{E}+\mathbf{v} \cdot \nabla \mathbf{B}
$$

および

$$
\frac{\mathrm{D} \mathbf{v}}{\mathrm{Dt}}=\mathrm{e}\left(\frac{1}{\mathrm{~m}}+\frac{1}{\mathrm{M}}\right)(\mathrm{E}+\mathbf{v} \times \mathbf{B}-\eta \mathrm{j})-\frac{(\mathrm{M}+\mathrm{m})^{2}}{\mathrm{Mm}} \nabla\left(\mathrm{U}+\frac{\mathrm{P}}{\rho}\right)
$$

である。（18) 式において比抵抗に比例する項は変分では出ててないてとに注意しておく。K積分の 場合と同様に一般化オーム則を仮定するとM積分の時間変化は

$$
\begin{aligned}
\frac{\mathrm{D}}{\mathrm{Dt}} \mathrm{M} & =\int \frac{\mathrm{D}}{\mathrm{Dt}}\left(\frac{1}{\rho} \mathbf{j} \cdot \mathbf{B}\right) \rho \mathrm{d} \boldsymbol{\tau} \\
& =\int\left[-\frac{(\mathrm{M}+\mathrm{m})^{2}}{\mathrm{Mm}} \mathrm{k}(\mathbf{B} \cdot \nabla) \mathrm{P}+\mathbf{j} \cdot(-\operatorname{rot} \mathbf{E}+\mathbf{v} \cdot \nabla \mathbf{B})\right] \mathrm{d} \boldsymbol{\tau}
\end{aligned}
$$

とかける。乙の積分内の第二項は一般化オーム則を使って以下のようにかきかえられる。

$$
\begin{aligned}
& \mathbf{j} \cdot\{-\eta \operatorname{rot} \mathbf{j}+\operatorname{rot}(\mathbf{v} \times \mathbf{B})+\mathbf{v} \cdot \nabla \mathbf{B}\} \\
= & -\eta \mathbf{j} \cdot \operatorname{rot} \mathbf{j}+\mathbf{j} \cdot\{-\mathbf{B} \operatorname{div} \mathbf{v}+(\mathbf{B} \cdot \nabla) \mathbf{v}\} \\
= & -\eta \mathbf{j} \cdot \operatorname{rot} \mathbf{j}+\mathrm{k}\{\rho \mathbf{v} \cdot(\mathbf{B} \cdot \nabla) \mathbf{v}-\rho(\mathbf{v} \cdot \mathbf{B}) \operatorname{div} \mathbf{v}\} \\
= & -\eta \mathbf{j} \cdot \operatorname{rot} \mathbf{j}+\mathrm{k}\left\{\frac{1}{2} \operatorname{div}\left(\rho v^{2} \mathbf{B}\right)-\frac{1}{2} \mathrm{v}^{2} \mathbf{B} \cdot \nabla \rho-(\mathbf{v} \cdot \mathbf{B})(\operatorname{div} \rho \mathbf{v}-\mathbf{v} \cdot \nabla \rho)\right\}
\end{aligned}
$$

この最後の関係で

$$
\begin{aligned}
& \mathbf{B} \cdot \nabla \rho=\mathbf{j} \cdot \nabla \rho=0 \\
& \operatorname{div} \mathbf{j}=\operatorname{div} \rho \mathbf{v}=0
\end{aligned}
$$

という二つの条件を使うと $\mathrm{M}$ 積分の時間変化は

$$
\frac{\mathrm{DM}}{\mathrm{Dt}}=-\eta \int \mathbf{j} \cdot \operatorname{rot} \mathbf{j} \alpha \tau+\int\left\{-\mathrm{e}\left(\frac{1}{\mathrm{~m}}+\frac{1}{\mathrm{M}}\right) \mathbf{B} \cdot \nabla \mathrm{P}+\frac{1}{2} \frac{\mathrm{e}}{\mathrm{M}+\mathrm{m}} \operatorname{div}\left(\rho \mathrm{v}^{2} \mathbf{B}\right)\right\} \mathrm{d} \tau
$$

とかける。右辺の二番目の積分は $\mathbf{B} ・ \mathbf{n}=0$ という条件で消え, 結局

$$
\frac{\mathrm{DM}}{\mathrm{Dt}}=-\eta \int \mathbf{j} \cdot \operatorname{rot} \mathbf{j} \mathrm{d} \tau=-\eta \int \mathbf{j} \cdot \Gamma \mathrm{d} \tau
$$

となり, 比抵抗 $\eta=0$ でM積分は保存する。条件（20)は問題ないが，（19）の条件は既に述べ 
たように少くともプラズマが平衡であれば満足されるものである7)。

§5. KおよびM積分の時間変化

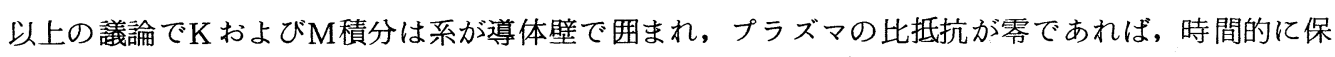
存するととがわかった。さらに比抵抗が零でない時, てれら helicity 積分が時間的に增大するのか 減少するのかという問題は極めて興味があるけれど，今日までそのような仕事は見当らないようであ

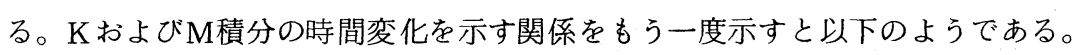

$$
\begin{aligned}
& \frac{\mathrm{D}}{\mathrm{Dt}} \int \mathbf{A} \cdot \mathbf{B} \mathrm{d} \tau=-2 \eta \int \mathbf{j} \cdot \mathbf{B} \mathrm{d} \tau \\
& \frac{\mathrm{D}}{\mathrm{Dt}} \int \mathbf{j} \cdot \mathbf{B} \mathrm{d} \tau=-\eta \int \boldsymbol{\Gamma} \cdot \mathbf{j} \mathrm{d} \tau
\end{aligned}
$$

これらの関係を扱うためには電流とベクトルポテンシャル, あるいは電流の渦度と磁界との関係がわ かるととが必要である。乙れらの関係を示唆するものとして著者の二流体変分原理によって得られた 一つの関係

$$
\mathbf{v}=\nabla \phi-\mathrm{e}\left(\frac{1}{\mathrm{~m}}+\frac{1}{\mathrm{M}}\right) \mathbf{A}
$$

が適当であろう。 $\mathbf{v}$ はイオンと電子の相対速度, 中は速度ポテンシャルであり, A はベクトルポテン シャルである。との関係は超電導におけるロンドンの式の一般化とでもいうべきもので, 事実ロンド

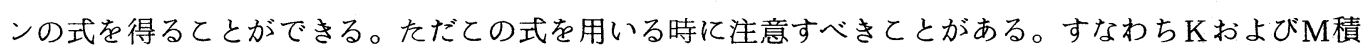
分はたとえば外部導体によって与えられたベクトルポテンシャルあるいは外部磁界は境界条件によっ て消去されているが，（22）式あるいはそれから導かれる関係には含まれているのである。そてで

$$
\mathbf{A}=\mathbf{A}_{\mathrm{O}}-\mathbf{A}
$$

として, $\mathbf{A}_{\mathrm{O}}$ は外部電流によるものとし, Aをプラズマ中の誘導場とすれば $(22)$ 式においてべクト ルポテンシャルの符号をかえておく必要がある。その上で $(22)$ 式から電流を作り, 磁界べクトルと のスカラー積を作れば

$$
\mathbf{j} \cdot \mathbf{B}=-\frac{\mathrm{e}}{\mathrm{M}+\mathrm{m}} \rho \mathbf{B} \cdot \nabla \boldsymbol{\phi}+\frac{\mathrm{e}^{2}}{\mathrm{Mm}} \rho \mathbf{A} \cdot \mathbf{B}
$$

という関係が得られ, 両辺の体積積分を行うと右辺第一項は境界条件と $\mathbf{B} ・ \nabla \rho=0$ という関係で零 となる。そとで, 


$$
\frac{\mathrm{D}}{\mathrm{Dt}} \int \mathbf{A} \cdot \mathbf{B} \mathrm{d} \tau=-2 \eta \frac{\mathrm{e}^{2}}{\mathrm{Mm}} \int \rho \mathbf{A} \cdot \mathbf{B} \mathrm{d} \tau
$$

という関係が導びかれる。もしのが定数とすれば電子ーイオン衝突数として上式は

$$
\frac{D}{D t} K=-\nu K
$$

となり

$$
K=K_{0} e^{-\nu t}
$$

が結論される。すなわち K 積分は時間とともに減少する。続いて $M$ 積分の議論に入る。

$$
\mathbf{j}=\frac{\mathrm{e}}{\mathrm{M}+\mathrm{m}} \rho \mathbf{v}
$$

の両辺の転回を作ると

$$
\operatorname{rot} \mathbf{j}=\boldsymbol{\Gamma}=\frac{\mathrm{e}}{\mathrm{M}+\mathrm{m}}(\rho \operatorname{rot} \mathbf{v}+\nabla \rho \times \mathbf{v})
$$

(22) 式から

$$
\operatorname{rot} \mathbf{v}=-e\left(\frac{1}{m}+\frac{1}{M}\right)\left(B_{o}-B\right)
$$

さらに平衡の式から

$$
(\nabla \rho \times \boldsymbol{\nabla}) \cdot \mathbf{j}=0
$$

を考虑して

$$
\boldsymbol{\Gamma} \cdot \mathbf{j}=\frac{\mathrm{e}^{2}}{\mathrm{Mm}} \rho\left(\mathbf{B}-\mathbf{B}_{\mathrm{o}}\right) \cdot \mathbf{j}
$$

が得られる。両辺を積分すると真空磁界は消え,

$$
\int \boldsymbol{\Gamma} \cdot \mathbf{j} \mathrm{d} \tau=\frac{\mathrm{e}^{2}}{\mathrm{Mm}} \int \rho \mathbf{j} \cdot \mathbf{B} \mathrm{d} \tau
$$

となる。そてで

$$
\frac{\mathrm{D}}{\mathrm{Dt}} \int \mathbf{j} \cdot \mathbf{B d} \boldsymbol{\tau}=-\eta \frac{\mathrm{e}^{2}}{\mathrm{Mm}} \int \rho \mathbf{j} \cdot \mathbf{B} \mathrm{d} \tau
$$


が導かれる。K積分の場合と同様 $\rho$ を定数とすれば

$$
M=M_{O} e^{-\frac{1}{2} \nu t}
$$

が結論され，M積分も時間とともに減少するがその時定数はK 積分のそれよりゆるやかである。

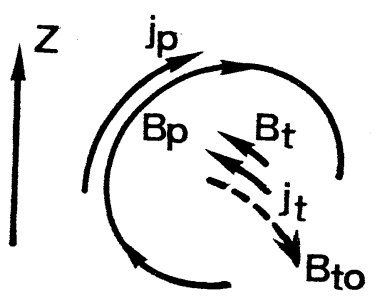

第 4 図

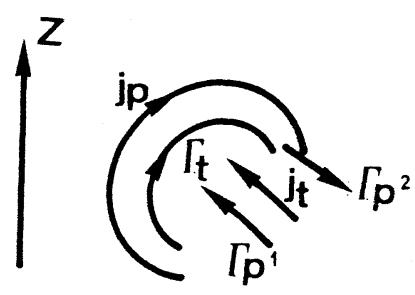

第 5 図

とのような議論が成立するためには，例えば(6)式にお いてK 積分とM積分の符号が同じでなければならない。 例を軸対称トーラス系にとって確かめておく。第四図に おいて真空トロイダル磁界 $\mathrm{B}_{\mathrm{to}}$, トロイダル磁界 $\mathrm{B}_{\mathrm{t}}$, 卜 ロイダル電流 $\mathrm{j}_{\mathrm{t}}$, ポロイダル磁界 $\mathrm{B}_{\mathrm{p}}$, ポロイダル電流 $\mathrm{j}_{\mathrm{p}}$ の向きが示してある。磁力線 $\mathrm{B}_{\mathrm{t}}$ と $\mathrm{B}_{\mathrm{p}}$ のからみ合い は正であり, 電流 $\mathrm{j}_{\mathrm{t}}$ と $\mathrm{j}_{\mathrm{p}}$ のからみ合いも確かに正であ る。第五図にトロイダル電流の作る渦ベクトル $\Gamma_{\mathrm{t}}$, ポ ロイダル電流の渦ベクトル $\Gamma_{\mathrm{p}}$ および $\mathrm{j}_{\mathrm{t}}, \mathrm{j}_{\mathrm{p}}$ の向き を示した。 $\Gamma_{\mathrm{t}}$ は一方向きであるが， $\Gamma_{\mathrm{p}}$ は磁気軸を囲 むポロイダル電流のピーク值に囲まれる領域の $\Gamma_{\mathrm{p} 1}$ と電 流值の下がる外の領域での $\Gamma_{\mathrm{p}^{2}}$ は向きが反対である。 すなわち $\Gamma_{\mathrm{p} 1}$ と $\Gamma_{\mathrm{t}}$ は正にからみ合うけれど， $\Gamma_{\mathrm{p}^{2}}$ と $\Gamma_{\mathrm{t}}$ は負にからみ合う。しかし（25) 式からわかるよう

に磁気軸近傍が密度が高いため全体として正になるととが予想される。てのように負のからみ合せの 領域が存在するため $M$ 積分の時間変化は $\mathrm{K}$ 積分のそれよりゆるやかになるのである。一方 $\mathrm{K}$ 積分も $\mathrm{M}$ 積分もプラズマの密度が中心で高くなるほど減衰が大きく，逆に平担なプロフィルほど，ゆるやかに なる。現在との理論は不安定性と結びついていないけれど, 非常に興味のあるととである。

\section{§6. あとがき}

この研究はふりかえってみると電流の渦度の研究に始まり, またそれで終ったような気がする。す なわちFRC の理論研究を電流の渦度の立場から行っているうち, その平衡解に helicity が含まれ ているととに気付いた。そこで改めて変分原理を組み上げ，KおよびM積分を副条件に入れるてとに 成功した。その上で $\mathrm{K}$ 積分, M積分の時間変化を調べているうちにまた電流の渦度の議論をせざるを 得なくなったのである。

helicity の文献を調べているうちに気付いたととがある。それは平衡配位と結びつける議論が少 


\section{Helicity 積分について}

ないととで，もともと天体物理の研究者が関心をもっているからではないかと考光る。天体現象は境 界条件が簡単なかわり，人間が細工するてとが不可能でそのため不変量を探したりまた関心をもつて とになるのかもしれない。しかしての研究によれば, 各種の helicity はいままでいわれてきたよう な低ベータプラズマよりもむしろ高ベータ研究に必要な概念のように思われる, 各種閉じ込め装置に 共通な思想としてもっと研究されねばならないだろう。そのためには, こてで用いてきた従来の境界 条件は再検討が必要であると考える。

$$
\text { 参考文献 }
$$

1) L. Woltjer : Rev. Modern Phys. 32 No. 4 (1960) 914.

2) H. K. Moffatt: J. Fluid Mech. 35 part 1 (1969) 117.

3) J. B. Taylor : Proc. 5 th International Conf. on Plasma Phys. and Contr. Nuclear Fusion Research, Tokyo Vol 1. (1974) 161.

4) A. Bhattacharjee and R. L. Dewar: Phys. Fluids 25 (1982) 887.

5) H. Itô : Jour. Phys. Soc. Japan (letter), 投稿中.

6) H. Itô : Progr. Theor. Phys. 48 No. 5 (1972) 1442.

7) H. Rund et al : J. Plasma Phys. 20. part 3 (1978) 329. 